\title{
Clinical experiences after the insertion of a Cyclosporine-A drug delivery device in horses with Equine Recurrent Uveitis
}

\author{
Helena Waid', József Tóth², Lieke Buijs² and Gerald Fritz Schusser ${ }^{3}$ \\ 1 Tierklinik Wahlstedt GmbH, Wahlstedt, Germany \\ 2 Tierärztliches Kompetenzzentrum Karthaus, Dülmen, Germany \\ ${ }^{3}$ Medizinische Tierklinik, Veterinärmedizinische Fakultät, Universität Leipzig, Germany
}

\begin{abstract}
Summary: Several studies have dealt with the etiopathogenesis-, diagnostics as well as the conservative and surgical treatment methods of equine recurrent uveitis (ERU) with different outcomes. Because of potential side effects of applied medication, the risk of doping in the case of sport horses and the problem of future uveitis episodes, a traditional medical treatment is not always feasible. This circumstance requires other promising therapeutic approaches, such as the pars plana vitrectomy (PPV) and the insertion of a cyclosporine-A (CsA) drug delivery device. The literature provides varying perspectives on both of the aforementioned methods. Besides the successful PPV, the cyclosporine-A implant is proposed and applied with an increased frequency due to its nature of being an easier and financially lucrative surgical technique. Currently cyclosporine implants cannot be obtained and applied legally in Germany, therefore any usage is signified as a serious breach of the Medicines Law. According to the literature it appears that the majority of authors consider the PPV to be an effective treatment method only for leptospira positive tested horses, but nor for eyes testing negative for leptospiral antibodies. This retrospective study included 24 ERU patients of different age, gender and breeds that were initially examined by ophthalmological specialists beforehand and treated with suprachoroidal CsA implants. These horses having the CsAl still suffered from uveitis episodes, as the implant only masked inflammatory bouts resulting in a proceeding damage of intraocular structures. This circumstance required another therapeutic approach. Undiluted vitreous humor samples of all of the 24 horses were taken and were tested for specific antibodies against 9 different serovars of Leptospira interrogans by microscopic agglutination test (MAT). The ERU-diseased eyes of 4 horses were removed and in one horse an intrascleral eye prosthesis was inserted. Between 2013 and 2017 19/24 horses with ERU (79.2\%) with CsA implants, still having uveitis episodes, were treated via single port PPV. The outcome of the PPV and the postoperative course of the horses were followed up. The evaluation of efficacy of the PPV was deduced either directly by follow-up examinations $(n=8)$, photographic documentation and patient records or indirectly by questioning the referring owners $(n=11) .14 / 19$ horses $(73.7 \%)$ were tested positive for intraocular leptospira antibodies and $5 / 19$ horses $(26.3 \%)$ have been tested intraocular MAT negative. The absence of active uveitis was considered a success irrespective of the visual outcome of the surgical treated eyes. A total of 14/19 horses (73.7\%) remained relapse-free over a period of 5 to 63 months. $10 / 14$ horses (71.4\%) with leptospiral antibodies in the vitreous humor had no further uveitis relapses postoperatively, while only $1 / 5$ horses $(20 \%)$ tested MAT negative continued to episodes of ERU. The comparison between numbers of horses with positive or negative leptospiral antibodies in vitreous humor in relation with or without recurrence of uveitis after PPV was not significantly different $(P=1.0)$ using twosided Fisher's exact test. According to these findings, it is doubted to perform a PPV depending on the leptospiral antibody result. In none of the 24 horses the implant slowed down the progression of uveitic destruction and a therapeutic success could not be achieved at all. This study yields promising results that the PPV should be the selected treatment method instead of the CsA implant.
\end{abstract}

Keywords: horse, eye, equine recurrent uveitis, vitrectomy, cyclosporine A, leptospira antibodies

Citation: Waid H., Tóth J., Buijs L., Schusser G. F. (2018) Clinical experiences after the insertion of a Cyclosporine-A drug delivery device in horses with Equine Recurrent Uveitis. Pferdeheilkunde 34, 113-120; DOI 10.21836/PEM20180202

Korrespondenz: Prof. Dr. Dipl. ECEIM Gerald Fritz Schusser, Medizinische Tierklinik, An den Tierkliniken 11, 04103 Leipzig, Germany; schusser@vetmed.uni-leipzig.de

\section{Introduction}

Equine recurrent uveitis (ERU) is the most common cause of blindness in horses (Gilger et al. 2010). It is characterized by chronic, recurrent episodes of inflammatory processes of iris, ciliary body and choroid. ERU is a T-helper type 1 (Th1)-mediated disease that is similar to some types of human uveitis (Gilger et al. 1999, Deeg et al. 2008). As determined in the North Carolina State University (NCSU) laboratory, ERU develops following primary uveitis when the blood-ocular barrier is disrupted and CD4+ T-lymphocytes enter and remain within the eye (Gilger et al. 1999).

The cause of ERU has not definitively been proven yet, but many infectious diseases have been associated with the onset of acute uveitis. These include onchocerciasis, leptospirosis,
Rhodococcus equi, brucellosis, toxoplasmosis, salmonellosis, equine herpes virus 1 and equine viral arteritis (Brooks 1999, Schwink 1992). Of these infectious diseases leptospirosis and primarily L. interrogans serovar Pomona and L. interrogans serovar Grippotyphosa have been mostly investigated (Brooks 1999, Schwink 1992, Dorrego-Keiter et al. 2016). Approximately in $20 \%$ of involved horses the disease occurs bilaterally (Brooks 2002a). Both eyes can be infected simultaneously, as well as completely independent from one another (Tóth et al. 2010).

The clinical signs of these horses are variable. Chronic gradual processes can allow longstanding vision, despite repeated inflammatory bouts. On the other hand, severe inflammatory bouts that follow closely one after the other can result in retinal degeneration, fibrin formation within the pupil and 
consequent loss of vision. Severe cases can lead to phthisis bulbi (von Borstel et al. 2005 and 2010, Tóth et al. 2010). ERU affected horses frequently show signs of blepharospasm, conjunctival hyperaemia, aqueous flare, posterior synechiae, cataract formation and chorioretinitis (Tóth et al. 2010).

A diagnosis of ERU is based on both, the clinical picture and a documented history of recurrent episodes of inflammation. Symptomatic treatments used for ERU (i.e. corticosteroids, mydriatics and non-steroidal anti-inflammatory medications) are aimed to reduce the inflammatory process and minimize the persistent ocular damage during each active episode (Tömördy et al. 2010). Unfortunately those treatments are not effective in the prevention of uveitis relapses, even an aggressive therapy is often insufficient to prevent further uveitis episodes (Tömördy et al. 2010). This circumstance requires other promising therapeutic approaches, such as the pars plana vitrectomy and the insertion of a cyclosporine-A (CsA) drug delivery device. Since 1991 the pars plana vitrectomy has been increasingly employed in the treatment of ERU diseased horses (Werry and Gerhards 1991, Winterberg 1997, Frühauf et al. 1998, Gilger and Spiess 2006, Dorrego-Keiter et al. 2017).

Besides the successful pars plana vitrectomy, the CsA-implant is proposed and applied with an increased frequency due to its nature of being an easier and financially more lucrative operation technique. Over the last few years, in both human and veterinary ophthalmology, a CsA containing siliconematrix has been used in clinical research studies (Davis et al. 2004, Kim et al. 2005, Gilger et al. 2006, Lee et al. 2007, Boehringer et al. 2009).

The literature recommends the vitrectomy only for the treatment of horses with a leptospira-associated ERU (Tömördy et al. 2010). Despite this suggestion, the clinical experiences and the results described by Dorrego-Keiter et al. (2017) indicate that the vitrectomy is effective in MAT-negative cases as well. In 2016 Baake et al. analysed the results of indirect and direct procedures to confirm the existence of leptospira using 98 samples of vitreal humor from horses with ERU (MAT, PCR, culture). The samples were grouped and sent to three different laboratories. The aim of this study was to investigate whether different laboratories have an influence on the frequency of leptospiral DNA and leptospiral antibody detection from samples of vitreal humor in horses suffering from ERU. The results of this study indicated a strong inter-laboratory agreement when using PCR for the detection of leptospiral DNA, whereas the detection of leptospiral antibodies via MAT showed varying results between two laboratories, complicating the interpretation. A falsely assessed, negative result may lead to the outcome that an ERU diseased horse will not undergo a PPV, if the decision is based only upon a positive MAT result. Basing a decision against PPV only upon a negative MAT from a single laboratory is not recommended. The credibility of the laboratory results are to be heavily questioned and the outcome for the patient may be severe as further episodes of increased inflammation and ultimately blindness may occur.

In the present study determines the experiences with CsA treated horses and evaluates the outcome of the vitrectomy in the case of both intraocular MAT positive and negative tested horses with ERU. Furthermore it was the goal of this study to determine whether a vitrectomy would be effective even in the case of MAT-negative ERU.

\section{Pars Plana Vitrectomy (PPV)}

The pars plana vitrectomy (PPV), which has been taken over from the human medicine, has first been described in 1991 for the management of equine recurrent uveitis (Werry and Gerhards 1991). Since then, PPV has been increasingly and successfully employed in the treatment of ERU in Europe (Werry and Gerhards 1991, Winterberg 1997, Frühauf et al. 1998, Gilger and Spiess 2006). A PPV should be performed in horses that suffered from at least two inflammatory bouts or in horses in which clear clinical changes in terms of ERU have been determined (Baumgart and Gerhards 2014). The PPV is no-indicative nor useful, if a progressed cataract formation or a phthisis bulbi is already present (Baumgart and Gerhards 2014). In those cases an enucleation of the bulbus would be indicated, in order to save the horse from painful inflammatory episodes (Gerhards and Wollanke 2001). With the usage of the PPV, opacities of the vitreal body as well as inflammatory products or mediators can be removed from the vitreous body's collagenous meshwork.

This collagenous meshwork represents an ideal framework for the accumulation and persistency of a variety of cellular and organic mediators of active and chronic inflammations. With the removal of the vitreous body's framework and the attached cells (T-lymphocytes) it is possible to remove immunocompetent material (antigens). The vitrectomy enables a significantly improved vision, as well as the flushing out of existing leptospira together with the prevention of recurrence. During the PPV, the vitreous body is cut into small pieces, aspirated and then flushed and replaced with Balanced Salt Solution $\left(\mathrm{BSS}^{\circledR}\right)$ mixed with Gentamycinsulphate $(0,08 \mathrm{mg} / \mathrm{ml})$ (Werry and Gerhards 1991). As a result of this the eye itself is able to remove the few remaining bacteria of leptospira. Wollanke et al. (2004) reported, leptospiral antibodies were not present anymore after one year post vitrectomy. Recurrent inflammatory bouts can be effectively prevented.

After the PPV no inflammatory bouts occurred in $71-97 \%$ of the horses (Frühauf et al. 1998, Tömördy 2009, von Borstel et al. 2005, Winterberg and Gerhards 1997, Tömördy et al. (2010) reported about more successful outcomes in the case of leptospira positive horses than in the case of leptospira negative patients. In $82.5 \%$ of the leptospira positive horses, the vitrectomy prevented further inflammatory episodes. Whereas these were only possible in leptospira negative patients (17.5\%). This is the reason why they recommend a PPV only for leptospira positive horses. On the other hand, the success of Ohnesorge et al. (2013) contradicts this theory, as in his studies only half of the PPV treated horses had leptospira positive vitreous samples.

In a recent study of Dorrego-Keiter et al. (2017) long-term results of the PPV in relationship to leptospiral antibody detection in vitreous humor samples of 118 horses with equine recurrent uveitis were evaluated. In this retrospective study of 118 ERU diseased patients of different age, gender and breed undiluted vitreous humor was aseptically taken at the 
beginning of the PPV and examined by culture, as well as by microagglutination test (MAT). Furthermore serum was taken and tested against specific antibodies against different serovars of $\mathrm{L}$. interrogans. All of the 118 horses were treated via single port pars plana vitrectomy. A total of 90 of 118 horses $(76.3 \%)$ remained relapse-free over a follow-up time of 8 to 54 month. In 42/49 horses (83.7\%), tested positive for leptospiral antibodies via MAT, and 49/69 horses, that tested negative, no further uveitis relapses could be detected. According to these findings Dorrego-Keiter et al. (2017) stated that a vitrectomy should be performed in accordance to the clinical ERU diagnosis, irrespectively from the leptospiral antibody result of the aqueous humor.

\section{Cyclosporine A implant}

Another currently used surgical option for the symptomatic treatment of horses with equine recurrent uveitis is the application of a suprachoroidal CsA implant. With the placement of this drug delivery device it is possible to achieve high CsA concentrations within the vitreous body. The human and veterinary ophthalmology deals with clinical research projects concerning the safety, long-term efficacy, complications and duration of effect of CsA containing implants made out of a silicon matrix (Davis et al. 2004, Kim et al. 2005, Gilger et al. 2006, Lee et al. 2007, Boehringer et al. 2008, Gilger et al. 2010). The CsA is an immunosuppressive drug that blocks the interleukin-2 transcription through the inhibition of calcineurin and impairs the proliferation of activated T-helper and T-cytotoxic cells (Kay 1989).

Since ERU is a T-cell-mediated disease (Gilger 1999, Deeg 2001, Deeg 2002). CsA may be an effective drug to prevent the reactivation of ocular inflammatory episodes characteristic for ERU. Due to the blockage of T-lymphocytes and bypassing the blood-ocular barrier a constant therapeutic concentration of $\mathrm{Cs}$ A can be maintained within the eye. Because of its hydrophobe character, cyclosporine cannot penetrate the eye when it is applied topically (Gilger 2005). An implant was developed which can be used in the suprachoroidal space. The advantages of this implant are that a constant concentration of cyclosporine can be maintained intraocular, the blood-ocular barrier is bypassed and the veterinarian is not dependent on the owner's compliance. The cyclosporine drug delivery device proved to be appropriate in the veterinary ophthalmology. It was very effectively inserted in the case of two immune-mediated eye diseases: the keratoconjunctivitis sicca in dogs and ERU (Acton et al. 2006, Gilger et al. 2010).

Briefly, the cyclosporine suprachoroidal implant (CSI) is placed between the sclera and the choroidea under general anesthesia (Tóth et al. 2010). In a few horses local and regional anesthesia (e.g. frontal and retrobulbar block) is successfully used (Gilger et al. 2010). In 2006, Gilger et al. reported on the usage of a suprachoroidal placement of a novel CsA sustained-release drug delivery device for the treatment of ERU. This is particular effective in horses that frequently show relapses of ERU or that show relapses directly after setting off the medication. After approximately 24 to 30 months the action of the implant decreases (Gilger and Spiess 2006).

Data from over 150 surgically treated horses showed, that it took approximately 30 days until therapeutic concentrations of CsA were set free (Gilger and Spiess 2006). In approximately $70 \%$ of the patients a complete control of the uveitis was achieved during this time. In the remaining cases very slight relapses occurred, which could be quickly managed. Gilger et al. reported in 2006 that the incidence of uveitis episodes can be reduced from 0.54 per month to 0.09 per month. It is notable, that only a few complications after the surgery, especially bleedings, retinal detachments or cataract formations, occurred. The implant is supposed to release CsA during 24 to 36 month.

Generally the successful outcomes, the easy surgical technique and the low risk of complications are aspects for using CsA implant as a very promising alternative in comparison to the more invasive vitrectomy. Gilger et al. (2010) reported about long-term outcomes (26 months) after the implantation of suprachoroidal CsA drug delivery devices in horses with ERU. In 133 horses and 151 eyes, that met the selection criteria for that study, one or more CsA implants were implanted. He compared his study with results reporting the longterm outcome in horses receiving standard care therapy (Dwyer 1998, Dwyer et al. 2005). In the course of Dwyer's study (1998) $81 \%$ of the Appaloosas (32/42 horses) receiving standard of care therapy became blind in one or both eyes from ERU. In the present work from Gilger et al. (2010) only $12 \%$ of the Appaloosa horses had loss of vision. Due to this comparison, the authors suggested, that the insertion of a CsA implant is particularly helpful in the prevention of blindness in Appaloosa horses with ERU. Regarding the nonAppaloosa breeds the comparison of long-term studies were less pronounced. ERU resulted in blindness in $47 \%(55 / 118)$ of the horses without implants, whereas $25 \%(28 / 114)$ of the horses with implants had vision loss. The authors suspect that in the case of a pronounced posterior uveitis along with changes in the vitreous body, a vitrectomy alone or together with the CsA implant would be necessary.

The results of this study have shown that the CsA implant decreases long-term vision loss of horses with ERU and decreases vision loss to a greater extent in Appaloosa horses. Baumgart and Gerhards (2014) discussed which form of therapy, either vitrectomy or CsA-implant would be more reasonable for uveitis treatment in Appaloosa horses, Knabstruppers and other horses of the Leopard type.

The suprachoroidal CsA implant should be particularly effective in the Appaloosa horse, which they think shows a special form of uveitis. These breeds and this coat color often come down with the insidious form of uveitis, which is not accompanied by painful inflammatory episodes and therefore is often recognized late. Because of this insidious disease the ophthalmic examinations frequently lead to diagnostic findings that point to a chronic disease. The proportion of leptospira negative test results was $55 \%$. Because of the less frequent involvement of leptospira infections in Appaloosa horses, Knabstruppers and Leopards, vitrectomy serves only for the removal of vitreous opacities, but not to prevent or stop further inflammatory episodes (Baumgart and Gerhards 2014).

The fact that a CsA implant does not help to remove leptospira from the eye and that they are still able to cause inflammatory episodes could possibly explain the lesser effect con- 
cerning the preservation of vision in non-Appaloosa breeds (Baumgart and Gerhards 2014).

Baumgart and Gerhards (2014) pronounce that a suprachoroidal CsA-implant with continuous release of CsA in the tissues and fluids of the eye could be particularly advantageous for horses with insidious uveitis in order to control chronic inflammatory processes, as a conservative therapy is hardly workable, due to missing external symptoms. According to Tömördy and Spiess (2010), the success of a vitrectomy in horses with ERU not associated with Leptospira spp. is considered to be doubtful and it is possible that these horses benefit from CsA implants (Gilger et al. 2000a, Gilger et al. 2000b, Gilger et al. 2001, Gilger and Spiess 2006, Gilger et al. 2006).

\section{Materials and Methods}

Test group: Criteria for the selection of cases

Between 2013 and 201724 horses with equine recurrent uveitis were examined and treated in the Tierärztliches Kompetenzzentrum Karthaus. All of the patients were initially examined by ophthalmological specialists beforehand. A presumptive diagnosis of ERU was made and a suprachoroidal CsA implant was placed lege artis. The 24 patients treated with the CsA implant were between 4 and 19 years old (9.9 \pm 2 years, mean). Eleven breeds of horses were included in this study, Warmbloods $(n=15)$, Iceland Horse $(n=4)$, Paint $(n=1)$, Frisian $(n=1)$, Andalusian $(n=1)$ and Leopard $(n=2)$. The test group consisted of seven mares and seventeen geldings.

\section{Clinical course}

All of the horses were treated with CsA implants 6 to 31 months before a complete ophthalmological examination was done at the Tierärztliches Kompetenzzentrum Karthaus. The owners of all horses recognized a very short non-inflammatory phase after the implantation. The progression of the

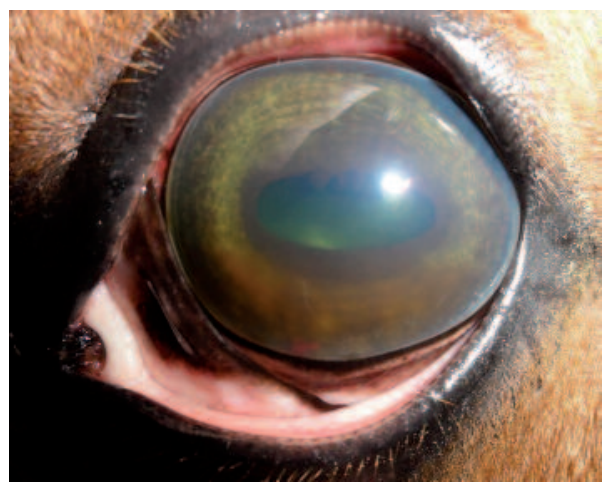

Fig. 1 Left eye of a 8 year old Oldenburg gelding with subacute uveitis in spite of Cyclosporin A implant. The pupil is contracted and iris had a yellowish discolouration. The episclera had marked vascularization. Opaque humor and blood can be seen in the ventral aspect of the anterior chamber. / Linkes Auge eines 8jährigen Oldenburger Wallaches mit subakuter Uveitis trotz Cyclosporin-A Implantation. Die Pupille ist miotisch und die lris ist gelblich verfärbt. Die Episklera weist eine deutliche Gefäßeinsprossung auf und die vordere Augenkammer ist mit trübem Kammerwasser und Blut gefüllt. inflammatory bouts was masked, barely painful. A few owners recognized dramatic changes only during the late phase. In two horses only a yellowish discoloration of the eye caused by the inflammation was observed by the owner (Fig. 1). The owners of 6 horses reported a constant and slight inflammation whereby the behaviour of those horses changed over time: the horses showed difficulties during work, they showed signs of head shaking and nervousness. In one of the horses a bleeding in the anterior chamber of the eye (hyphema) occurred 20 months after the implantation of CsA.

\section{Ophthalmological examination}

All of the 24 horses underwent an exact ophthalmological examination. Morphological findings were recorded and functional examinations were performed. During this complete examination in all of the horses a subacute uveitis was diagnosed. The pupil was slightly narrower than in the contralateral eye and in all of the horses a yellowish discoloration of the pupil was observable. In two of the horses a retinal detachment and in two horses a glaucoma was diagnosed (Fig. 2).

\section{Initial therapy}

Two eyes out of two horses were removed without further treatment due to particularly pronounced secondary glaucomas. Two further permanently painful and damaged eyes out of two horses (cataracta lentis, ablatio retinae, atrophia bulbi) have been removed upon the owner's request. In the case of a successful sport horse, an intrascleral eye prothesis was inserted. All of the other horses (19/24) were treated with a combined dexamethasone, neomycin sulphate and polymyxin $B$ sulphate containing eye ointment and topical atropin 1\% ointment after a subconjunctival administration of a combination out of dexamethasone $(3 \mathrm{mg})$, gentamycinsulphate $(20 \mathrm{mg})$ and atropinsulphate $1 \%(3 \mathrm{mg})$. As anti-inflammatory treatment the horses got Phenylbutariem ${ }^{\circledR} 100 \mathrm{mg} / \mathrm{ml}(2-4 \mathrm{~g}$ SID) (Pharma-Partner Vertriebs-GmbH Team, Hamburg, Germany) orally. After a 3-4 weeks long period without inflammatory episodes, a PPV was performed in 19/24 horses. It is important to emphasize that the reason to perform a PPV was the occurrence of recurring inflammatory bouts.

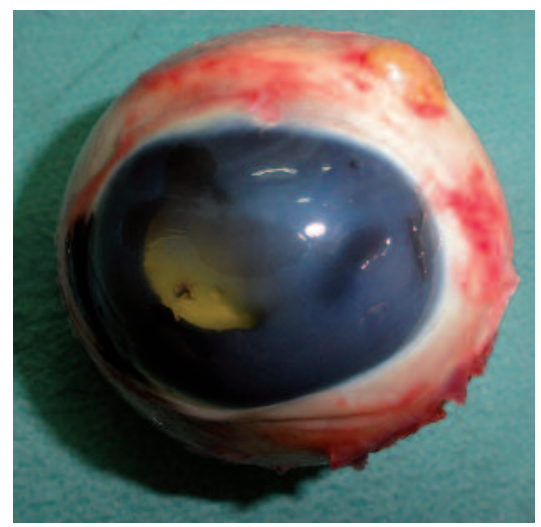

Fig. 2 Left eye of a uveitis-diseased 17 year old Leopard gelding with secondary glaucoma 12 months after implantation of Cyclosporine A. / Linkes Auge eines 17 iährigen Tigerschecken Wallachs mit Uveitis und sekundärem Glaukom 12 Monate nach Einsetzen eines Cyclosporin-A-Implantates 
The outcome of the vitrectomy and the postoperative course of the horses were followed up. The evaluation of efficacy of the PPV was deduced directly by follow-up examinations, photographic documentation and patient records, indirectly by questioning the referring owners. The follow-up period ranged from 5 months to 63 months. Vitreous humor samples ( $n=24$ eyes) of all of the 24 horses were collected, tested with MAT and submitted to the Bayerisches Landesamt für Gesundheit und Lebensmittelsicherheit, Veterinärstrasse 2, 85764 Oberschleissheim, Germany. A final titer of $\geq 1: 100$ was taken as a positive titer. The samples were tested for 9 different epidemiological relevant serovars: L. interrogans serovar Hardjo, L. interrogans serovar Canicola, L. interrogans serovar Grippotyphosa, L. interrogans serovar Icterohaemorrhagiae, L. interrogans serovar Pomona, L. interrogans serovar Bratislava, L. interrogans serovar Javanica, L. interrogans serovar Saxkoebing and L. interrogans serovar Pyrogenes.

Statistical analysis was done to compare numbers of ERUdiseased horses which had implantation before and removal of suprachoroidal CsA and PPV after frequency of uveitis episodes with or without leptospiral antibody titers in the vitreous humor in relation to recurrence or no recurrence of uveitis after PPV. Two sided Fisher's exact test was used for comparison and P-value $<0.05$ was considered significant.

\section{Results}

In the time between 2013 and 2017 19/24 horses, 7 mares and 12 geldings, had undergone a PPV. The suprachoroidal CsA implants placed in involved eyes of all 19 horses 6 to 31 months ago were removed before PPV (Fig. 3). 14 out of 19 horses $(73.7 \%)$ with ERU had intraocular leptospiral antibody titer whereas serovars Grippotyphosa, Pomona, Bratislava, Canicola, Saxkoebing and Icterohaemorrhagiae were tested positive. But 5/19 horses (26.3\%) had no intraocular leptospiral antibody titer. 10 out of 14 horses (71.4\%) showed no further uveitis relapses post operatively. 4 out of 5 horses (80\%) tested negative for leptospiral antibodies were considered as a success, as showed no further uveitis episodes (Tab. 1). 4/5 eyes from 5 horses which had been removed directly after the first examination at the horse hospital without vitrectomy were tested negative for intraocular leptospiral antibodies, while one eye was tested positive. In vitreous samples of 5 out of 19 horses (26.3\%) no leptospiral antibodies were evident. There was no significant difference between ERU diseased horses with or without recurrence of uveitis episodes after PPV in correlation to present or not present lepto- spiral antibodies in vitreous humor $(P=1.0$, using two-sided Fisher's exact test) (Tab. 1).

\section{Discussion}

The most important goal in the therapy of ERU is the prevention of recurrent inflammatory and painful episodes of acute uveitis. The medical treatment for the prevention of recurrent uveitis is usually insufficient on a long-term basis. The present study describes the clinical experiences with CsA implants in horses with ERU, the consecutively episodes of acute uveitis over a period of 6 to 31 months and the long-term outcome of these cases treated with PPV regardless of which leptospiral antibodies on vitreous humor were present or absent. The absence of recurrent uveitis episodes was taken as a success.

Overall, in 5 years 24 horses with ERU were examined and treated at the Tierärztliches Kompetenzzentrum Karthaus. It is important to emphasize that all of these horses have been initially provided with a CsA implant without being tested for intraocular leptospiral antibodies before the insertion. 19 (79.2\%) out of the 24 horses underwent a PPV. The performance of the vitrectomy resulted in the prevention of recurrent uveitis episodes in 10/14 horses (71.4\%) tested positive for intraocular leptospiral antibodies. Only one of the 5 horses tested negative for leptospiral antibodies continued to experience further episodes of ERU.

Studies to determine the long-term efficacy, complications and duration of effects of CsA in horses with ERU were per-

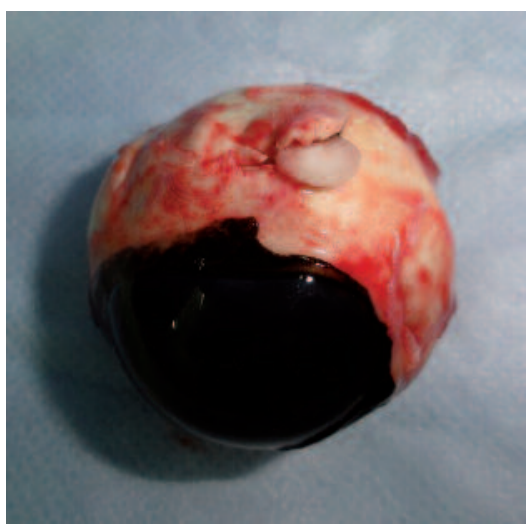

Fig. 3 Image of a surgically removed bulbus with a suprachoroidal placed Cyclosporine A implant. / Aufnahmen eines chirurgisch entfernten Bulbus mit suprachoroidal liegendem Cyclosporin-AImplantat

Tab. 1 Contingency table demonstrating the numbers of ERU-diseased horses with cyclosporine A implant but still with uveitis episodes and removal of cyclosporine A implant in connection with pars plan vitrectomy later on. The comparison of horses with or without recurrence of uveitis episodes within 5 to 63 months after pars plan vitrectomy in relation to leptospiral antibody detection in vitreous humor was not significantly different $(\mathrm{P}=1.0)$ using the two-sided Fisher's exact test. | Kontingenztabelle der ERU-kranken Pferde mit Implantation, jedoch mit Uveitisschüben, und Entfernung von Cyclosporin-A-Implantat sowie durchgeführter Pars-Plana-Vitrektomie nach 5 bis 63 Monaten. Zwischen der Anzahl der Pferde mit oder ohne Leptospiren-Antikörper-Titer in der Glaskörperflüssigkeit und Wiederauftreten oder Nicht-Wiederauftreten von nachfolgender Uveitis gab es keinen signifikanten Unterschied ( $P=1.0$; Fisher Exakter Test).

\begin{tabular}{cccc}
\hline Vitreous Humor & $\begin{array}{c}\text { Recurrence of Uveitis } \\
\text { after Pars Plana Vitrectomy }\end{array}$ & $\begin{array}{c}\text { No recurrence of Uveitis } \\
\text { after Pars Plana Vitrectomy }\end{array}$ & $\begin{array}{c}\text { Number of horses with ERU treated } \\
\text { via PPV after CsA implant removal }\end{array}$ \\
\hline With leptospiral antibody titer & $4(28.6 \%)$ & $10(71.4 \%)$ & 14 \\
Without leptospiral antibody titer & $1(20 \%)$ & $4(80 \%)$ & 5 \\
$\Sigma$ & $5(26.3 \%)$ & $14(73.7 \%)$ & 19 \\
\hline
\end{tabular}


formed (Gilger et al. 2010). Horses with ERU were treated with a 6-mm diameter, $25 \mathrm{mg}$, reservoir matrix CsA implant in the deep sclera adjacent to the suprachoroidal space (Gilger et al. 2010). The horses were followed-up more than one year for the frequency of uveitis episodes, complications and vision. Data from 151 eyes of 133 horses from the USA and Europe were reviewed. Gilger et al. (2010) reported that at last follow-up $78.8 \%$ of the eyes were considered visual and the mean frequency of recurrent uveitis episodes after CsA implantation was $0.09 \pm 0.08$ (mean \pm SD) episodes per month. The authors compared their results with those reporting about the long-term outcome in horses with ERU receiving standard care therapy (Dwyer 1998, Dwyer et al. 2005). They reported about the overall percentage of visual horses $(78.8 \%)$ at last follow-up which was nearly double of the overall percentage of visual horses (44\%) with ERU in Dwyer's study. Gilger et al. (2010) postulated that this comparison supports their results which stated the CsA implant improves the visual outcome in horses with ERU. The data in Gilger's as well as in Dwyer's study were evaluated separately for Appaloosa horses and non-Appaloosa horses. Dwyer's study has confirmed that particularly Appaloosa horses have a high risk of blindness (34 out of 42; $81 \%$ became blind in one or both eyes). According to Gilger the CsA implant seems to have a good effectiveness particularly in the Appaloosa horse with ERU. In his study only 4 out of 33 Appaloosas became blind in one or both eyes at last follow-up.

In the present study in all ERU-diseased horses with CsA implant a subacute uveitis was diagnosed later on. The pupil was slightly narrower than in the contralateral eye and in all of the horses a yellowish discoloration of the eye was observable. In two of the horses a retinal detachment and in two other horses a glaucoma was diagnosed. A hyphema was observed in one horse. These findings contribute to the statement of Gilger et al. (2010) that a CsA implant is suggested in horses with ERU to decrease long-term vision loss, as those patients account for a quite high percentage of our cases (20\%). From our perspective it is doubtful whether the other $80 \%$ would have lost vision as well without undergoing the PPV.

The majority of horses in Gilger's study were from the USA. It can therefore be assumed that the results of the CsA implantation are related to the situation in the USA. According to literary references, the prevalence of leptospiral infections in horses from the USA is lower and therefore CsA implants are used to reduce the frequency and severity of uveitis relapses and to prevent vision loss. With a number of 33 the Appaloosa horses were over-represented compared to the European horses, including Warmbloods and Hanoverians with a total number of 17. The present study included horses from different breeds, mainly Warmbloods from Europe (German Warmblood, $n=2$; Trakehner, $n=1$; Rhineland, $n=2$; Hanoverian, $n=3$; Westphalian, $n=4$; Oldenburg, $n=3$ ) with a total of 15 out of 24 horses. At this time the low number of horses from the USA in our study does not allow a direct comparison of outcome.

In view of the actual findings we determined, that a CsA implant in general cannot prevent loss of vision, it only helps to retain some vision while masking inflammatory bouts. At this time the authors share the results of Baumgart and Gerhards (2014) that in Appaloosa horses compared with other breeds the incidence of ERU is higher. They show a special type of uveitis (Baumgart and Gerhards 2014). Horses of endangered breeds e.g. Appaloosa horses, Knabstruppers or Leopards which are affected by insidious uveitis, are often presented when irreversible disturbances of vision have already occurred. Due to the fact, Appaloosa horses, Knabstruppers and Leopards are significantly less affected by leptospiral-associated ERU. The authors postulate that a CsA implant may be an advantage for such horses. At this time the authors are not able to agree with Baumgart and Gerhards and it still remains a matter of discussion whether a PPV or a CsA implant would be a more reasonable treatment of ERU in these breeds. Further studies would be necessary to determine the clinical efficacy. Nevertheless, the problem arising from this study will probably be that the number of Appaloosa horses in Germany is relatively low.

Existing data suggest that a PPV is an effective treatment for leptospiral-associated ERU, but not for horses tested intraocular L. interrogans negative (Tömördy et al. 2010). 47 eyes of ERU diseased horses were tested by MAT for various serovars of $L$. interrogans. The presence or absence of recurrent uveitis episodes was evaluated by repeated ophthalmological examinations as well as by questioning the referring veterinarians and owners. $85 \%$ of the horses were positive for intraocular antibodies against L. interrogans, mostly L. interrogans serovar Grippotyphosa. The majority of the leptospiral positive tested horses $(40 / 47 ; 82.5 \%)$ did not show further uveitis episodes, while 6 out of 7 horses (85.7\%) tested negative continued to show recurrent episodes of uveitis. Tömördy et al. (2010) assumes that a PPV is primarily successful in the case of leptospiral-associated ERU. Furthermore, the authors recommend the performance of a leptospiral antibody testing of vitreal and aqueous humor samples by MAT prior to a PPV.

Compared to Tömördy et al. (2010) our results showed a significantly different outcome of PPV in MAT negative tested horses. In their study the majority of horses tested leptospira negative $(85.7 \%)$ continued to future uveitis episodes again, as in our study the majority of MAT-negative horses (80\%) did not show further episodes of ERU. Besides this, Tömördy's study involved a longer follow-up (ranged from 3 months to 7.5 years) than our study (ranged from 5 month to 63 months). Additionally the lack of data concerning the breeds of the different horses in Tömördy's study does not allow a direct comparison to the outcome.

Despite these shortcomings, the present study demonstrates the successful outcome of the PPV even in the case of leptospiral negative horses. Based on the reported experiences one cannot share the opinion of Tömördy and Spiess (2010) that the success of a PPV in horses tested negative for intraocular leptospira is considered to be doubtful and hence a CsA implant is indicated in those horses. The success with 19 cases contradicts the assumption that a PPV is primarily successful in ERU-diseased horses with or without leptospiral antibodies in the vitreous humor. The presumption that eyes with leptospiral negative tested vitreous humor samples show less response to a PPV with regards to the prevention of further episodes of uveitis, is doubted due to the above named results. However the fact is that four eyes tested leptospiral negative needed to be removed directly, because the intraocular damage had progressed so far that a vitrectomy was 
no longer possible. In a recent study of Dorrego-Keiter et al. (2017) the aim was to elucidate the relationship between leptospiral antibody detection in vitreous humor and the success of PPV in horses with ERU. This retrospective study of 118 ERU patients confirmed that the therapeutic approach to perform a PPV is in accordance to the clinical ERU diagnosis and irrespective to the result of the leptospiral antibody testing.

It is not without significance that the cyclosporine is one of the prohibited substances on a national level (Deutsche Reiterliche Vereinigung since 2013), while internationally CsA implants are classified as "Controlled Medication Substances" (FEl, Fédération Equestre Internationale 2016a), meaning competing on international level is possible after completing the "Veterinary Form 2" (FEl 2016b). Horses with CsA implant are excluded from equestrian tournaments in Germany. Presently CsA containing drug delivery devices are non-licensed for horses on the European as well as on the American market. They are produced in the USA and it is illegal to obtain these implants due to pharmaceutical laws (Gesell 2016). CsA is a non-licensed drug for horses in Germany at this time. According to $\S 56$ a of the pharmaceutical law it would be theoretically possible to obtain implants, manufactured by certain pharmacies. But this proves to be rather difficult due to the complex galenics in case of such a longterm drug delivery device. In the event, that CsA implants would be authorized and available in Germany, they would be a good possibility in the treatment of the immune-mediated keratitis vasculosa. According to a study of Tóth et al. (2011), sport horses and patients suffering from recurring episodes of immune-mediated keratitis could benefit from the implant. Their study revealed that the CsA implant is an effective method to treat the recurrence of the immune-mediated keratitis.

Finally, the authors consider the CsA implants in warmblood horses with ERU do not present any viable alternative to the PPV. In the future we will continue with follow-up examinations of these horses as well as with the research investigating the effectiveness of PPV in both leptospiral negative and positive tested horses.

\section{References}

Acton A. E., Beale A. B., Gilger B. C., Stoskopf M. K. (2006) Sustained release cyclosporine therapy for bilateral keratoconjunctivitis sicca in a red wolf (Canis Rufus). J. Zoo Wildlife Med. 37, 562-564

Baake E. I. A., von Borstel M., Rohn K., Ohnesorge B. (2016) Detection of intraocular leptospiral DNA, antibodies and Leptospira spp. in horses with equine recurrent uveitis in different laboratories. Pferdeheilkunde 32, 346-356; DOI 10.21836/PEM20160407

Baumgart A., Gerhards H. (2014) Besonderheiten der Tiegerschekken-Uveitis und möglicher Cyclosporin A-Einsatz in deren Therapie in Deutschland. Pferdeheilkunde 30, 626-632; DOI 10.21836/PEM20140601

Boehringer D., Schwartzkopf J., Huber K., Joussen A., Seitz B., Lohmann C., Messmer E., Cursiefen C., Kruse F., Geerling G., Meller D., Noelle B., Reinhard T. (2009) Präventionen von Abstossungsreaktionen nach Keratolplastik mittels episkleralem Cyclosporin Afreisetzendem Medikamententräger: die Lucida Studien. 107. Kongr. Deutschen Ophthalmol. Ges. Leipzig, Germany

Brooks D. E. (1999) Equine ophthalmology. In: Gelatt K.N. (ed.): Veterinary Ophthalmology, 3rd ed. Baltimore, MD, Williams and Wilkins, 1053-1116

Brooks D. E. (2002a) Equine Ophthalmology. In Depth: Ophthalmology 48, 300-313
Davis J., Gilger B,. Robinson M. (2004) Novel approaches to ocular drug delivery. Curr. Op. Molec. Ther. 6, 195-205

Deeg C. A., Kaspers B., Gerhards H., Thurau S. R., Wollanke B., Wildner $G$. (2001) Immune responses to retinal autoantigens and peptides in equine recurrent uveitis. Invest. Ophthalmol. Vis. Sci. 42, 393-398

Deeg C. A., Ehrenhofe M., Thurau S. R., Reese S., Wildner G., Kaspers B. (2002) Immunopathology of recurrent uveitis in spontaneously diseased horses. Exp. Eye Res. 75, 127-133

Deeg C. A., Hauch S. M., Amann B., Pompetzki D., Altmann F., Raith A., Schmalzl T., Stangassinger M., Ueffing M. (2008) Equine recurrent uveitis - a spontaneous horse model of uveitis. Ophthal. Res. 40, 151-153

Deutsche Reiterliche Vereinigung e.V. Veterinämedizinische Änderungen im Pferdesport (2013)

Dorego Keiter E., Tóth J., Dikker L., Sielhorst J., Schusser G. F. (2016) Kultureller Nachweis von Leptospiren in Glaskörperflüssigkeit und Antikörpernachweis gegen Leptospiren in Glaskörperflüssigkeit und Serum von 225 Pferden mit equiner rezidivierender Uveitis (ERU). Berl. Münch. Tierärztl. Wschr. 129, 209-215

Dorrego Keiter E., Tòth J., Dikker L., Sielhorst J., Schusser G. F. (2017) Langzeitergebnisse der Pars-Plana-Vitrektomie in Anhängigkeit vom Leptospiren-Antikörper-Nachweis im Glaskörper bei 118 Pferden mit Equiner Rezidivierender Uveitis (ERU). Pferdeheilkunde 33, 112-118; DOI 10.21836/PEM20170201

Dwyer A. (1998) Visual prognosis in horses with uveitis. American Society of Veterinary Ophthalmology Annual Meeting, Chicago, IL. 22-23

Dwyer A., Gilger B. C. (2005) Equine recurrent uveitis. In: Equine Ophthalmology. Gilger B.C. (ed.) Elsevier, Philadelphia, PA, 42-62

FEl (2016) Equine Prohibited Substances List https://www. fei.org/sites/default/files/2017\%20Equine\%20Prohibited\%20Substances\%20List_0.pdf

FEI Veterinary Form 2 (2016) https://www. fei.org/system/files/Veterinary\%20Form\%202\%20-\%202016_0.pdf

Frühauf B., Ohnesorge B., Deegen E., Boeve M. (1998) Surgical management of equine recurrent uveitis with single port pars plana vitrectomy. Vet. Ophthal.1, 137-151

Gesell S. (2016) Therapie der ERU. Enke Verlag. Pferdespiegel 1, 26-33

Gilger B. C., Malok E., Cutter K., Stewart T., Horohov D., Allen J. B. (1999) Characterization of T-lymphocytes in the anterior uvea of eyes with chronic equine recurrent uveitis. Vet. Immunol. Immunopathol. 71, 17-28

Gilger B. C., Malok E., Stewart T., Ashton P., Smith T., Jaffe G. J., Allen J. B. (2000a) Long-term effect on the equine eye of an intravitreal device used for sustained release of cyclosporine A. Vet. Ophthal. 3, 105-110

Gilger B. C., Malok E., Stewart T., Horohov D., Ashton P., Smith T., Jaffe G. J., Allen J. B. (2000b) Effect of an intravitreal cyclosporine implant on experimental uveitis in horses. Vet. Immunol. Immunopath. 76, 239-255

Gilger B. C., Wilkie D. A., Davidson M. G., Allen J. B. (2001) Use of an intravitreal sustained-release cyclosporine delivery device for treatment of equine recurrent uveitis. Am. J. Vet. Res. 62, 1892-1896

Gilger B. C. (2005) Equine Ophthalmology, Elsevier Saunders, 285-322

Gilger B., Spiess B. M. (2006) Surgical Management of Equine Recurrent Uveitis. Equine Surgery. J. A. Auer, Stick, J. A. Philadelphia, WB Saunders, 749-755

Gilger B. C., Wilkie D. A., Clode A. B., Mcmullen R. J. Jr., Utter M. E., Komaromy A. M., Brooks D. E., Salmon J. H. (2010) Long-term outcome after implantation of a suprachoroidal cyclosporin drug delivery device in horses with recurrent uveitis. Vet. Ophthal. 13, 294-300

Kay J. (1989) Inhibitory effects of cyclosporin A on lymphocyte activation. In: Cyclosporin: Mode of Action and Clinical Application.Thomson A. (ed.) Kluwer Academic Publishers, Dordrecht, 1-23

Kim H., Csaky K. G., Gilger B. C., Dunn J. P., Lee S. S., Tremblay M., de Monasterio F., Tansey G., Yuan P., Bungay P. M., Lutz R. J. and Robinson M. R. (2005) Preclinical evaluation of a novel episcleral cyclosporine implant for ocular graft-versus-host disease. Invest. Ophthalmol. Vis. Sc. 46, 655-662 
Kulbrock M., Von Borstel M., Rohn K., Distl O., Ohnesorge B. (2013) Studie zur Häufigkeit und Schweregrad der Equinen Rezidivierenden Uveitis bei Warmblütern. Pferdeheilkunde 29, 27-36; DOI 10.21836/PEM20130105

Lee S. S., Kim H., Wang N. S., Bungay P. M., Gilger B. C., Yuan P., Kim J., Csaky K. G., Robinson M. R. (2007) A pharmacokinetic and safety evaluation of an episcleral cyclosporine implant for potential use in high-risk keratoplasty rejection. Invest. Ophthalmol. Vis. Sc. 48, 2023-2029

Schwink K. L. (1992) Equine uveitis. Vet Clin North Am, Equine Pract. 8, 557-574

Tömördy E. (2009) Long-term results after pars plana vitrectomy in horses with recurrent uveitis. Diss. Med. Vet. Zurich

Tömördy E., Hässig M., Spiess B. (2010) The outcome of pars plana vitrectomy in horses with equine recurrent uveitis with regards to the presence or absence of intravitreal antibodies against various serovars of Leptospira interrogans. Pferdeheilkunde 26, 251-254; DOI 10.21836/PEM20100222

Tóth J., Hollerrieder J., Sótonyi P. (2010) Augenheilkunde beim Pferd. Schattaver, 180-184

Tóth J., Huthmann S., Hollerrieder J. (2011) Clinical experience and long-term outcome after subscleral insertion of a cyclosporin A drug delivery device in horses with immune-mediated keratitis. Pferdeheilkunde 27, 589-596; DOI 10.21836/PEM20110603 von Borstel M., von Oppen T., Glitz F., Frühauf B., Deegen E., Boevé M. H., Ohnesorge B. (2005) Langzeitergebnisse der Pars plana Vitrektomie (double port) bei Equiner Rezidivierender Uveitis. Pferdeheilkunde 21, 13-18; DOI 10.21836/PEM2005 0102

von Borstel M., Oey L., Strutzberg-Minder K., Boevé M. H., Ohnesorge B. (2010) Direct and indirect detection of leptospires in vitreal samples of horses with ERU. Pferdeheilkunde 26, 219-225; DOI 10.21836/PEM20100217

Werry H., Gerhards H. (1991) Möglichkeiten der und Indikationen zur chirurgischen Behandlung der equinen rezidivierenden Uveitis (ERU). Pferdeheilkunde 7, 321-331; DOI 10.21836/PEM19910 602

Winterberg A., Gerhards H. (1997) Langzeitergebnisse der Pars-plana-Vitrektomie bei equiner rezidivierender Uveitis. Pferdeheilkunde 13, 377-383; DOI 0.21836/PEM19970409

Wollanke B., Rohrbach B. W., Gerhards H. (2001) Serum and vitreous humor antibody titers in and isolation of Leptospira interrogans from horses with recurrent uveitis. J. Am. Vet. Med. Assoc. $219,795-800$

Wollanke B., Gerhards H., Brem S., Meyer P., Kopp H. (2004) Etiology of equine recurrent uveitis (ERU): Autoimmune disease or intraocular leptospiral infection? Pferdeheilkunde 20, 327-340; DOI 10.21836/PEM20040403 